\title{
Health-Promoting Behaviors and Well Being among Middle-aged and Older Adults
}

Valerie K. Blake

Follow this and additional works at: https://researchrepository.wvu.edu/etd

\section{Recommended Citation}

Blake, Valerie K., "Health-Promoting Behaviors and Well Being among Middle-aged and Older Adults" (2014). Graduate Theses, Dissertations, and Problem Reports. 5222.

https://researchrepository.wvu.edu/etd/5222

This Thesis is protected by copyright and/or related rights. It has been brought to you by the The Research Repository @ WVU with permission from the rights-holder(s). You are free to use this Thesis in any way that is permitted by the copyright and related rights legislation that applies to your use. For other uses you must obtain permission from the rights-holder(s) directly, unless additional rights are indicated by a Creative Commons license in the record and/ or on the work itself. This Thesis has been accepted for inclusion in WVU Graduate Theses, Dissertations, and Problem Reports collection by an authorized administrator of The Research Repository @ WVU. For more information, please contact researchrepository@mail.wvu.edu. 
Health-Promoting Behaviors and Well Being among Middle-aged and Older Adults

\author{
Valerie K. Blake
}

\author{
Thesis submitted \\ to the Eberly College of Arts and Sciences \\ at West Virginia University \\ in partial fulfillment of the requirements for the degree of \\ Master of Science in \\ Lifespan Developmental Psychology \\ Julie Hicks Patrick, Ph.D., Chair \\ Elizabeth Kyonka, Ph.D. \\ Constance Toffle, Ph.D. \\ Department of Psychology
}

Morgantown, West Virginia

2014

Keywords: Health promotion, middle-age, older adults, physical activity, nutrition 


\begin{abstract}
Health-Promoting Behaviors and Well Being among Middle-aged and Older Adults
\end{abstract}

\author{
Valerie K. Blake
}

The primary goal of this study was to evaluate the influence of adherence to nutrition guidelines and engaging in regular physical activity on the physical and psychological dimensions of wellbeing in a sample of middle-aged and older adults. All available sociodemographic indicators were also analyzed in order to investigate potential interactions. A structural equation model was constructed utilizing data from 348 middle-aged and older adults who completed the Health Behavior and Knowledge Survey. Results indicated the model was a good fit to the data, accounting for $40.4 \%$ of the variance in physical well-being and $26.3 \%$ of variance in psychological well-being. Examination of individual paths within the model indicated complex interactions among variables involved in performance of health-promoting behaviors and in physical and psychological well-being, directly. Indications for future directions are discussed. 


\section{TABLE OF CONTENTS}

Page

TITLE

ABSTRACT. .ii

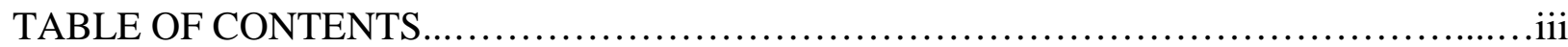

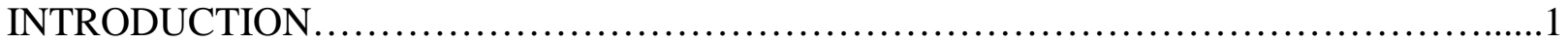

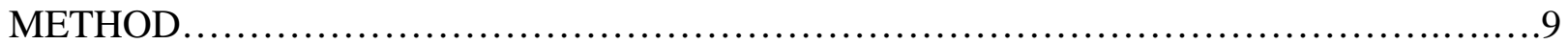

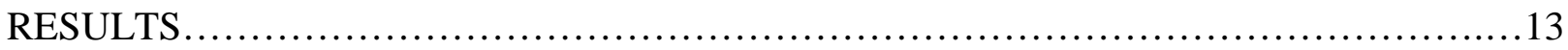

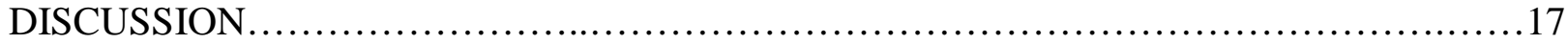

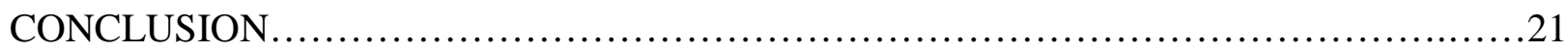

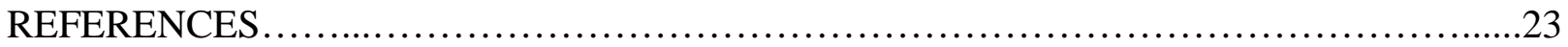

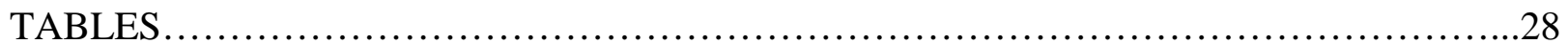

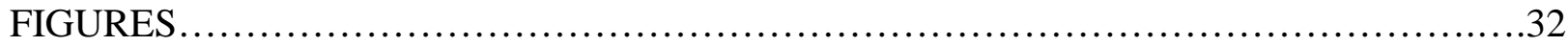

APPENDIX A, DESCRIPTIVE STATISTICS FOR DEMOGRAPHIC VARIABLES...........34

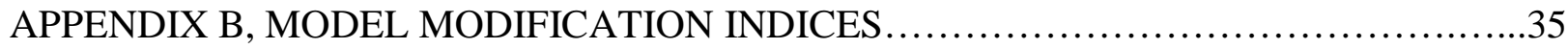

APPENDIX C, HEALTH BEHAVIOR AND KNOWLEDGE SURVEY ........................36 
Health-Promoting Behaviors and Well Being among Middle-aged and Older Adults Most people in the US today can expect to live longer than ever before in human history. Unfortunately, for many adults these additional years are associated with increased risk of chronic medical conditions or disability (Amarantos, Martinez, \& Dwyer, 2001; Drewnowski \& Evans, 2001). Thus, the indices of health traditionally used in research, such as morbidity and mortality, do not provide a complete picture of wellness in the aging population. In 1948, the World Health Organization (WHO) began to redefine our concept of health as more than just a lack of disease to what most recognize today as the dynamic interaction of physical, psychological, and environmental influences determining an individual’s quality of life. The concept of well being, a subjective appraisal of the overall quality of one's life, is more in line with the WHO conceptualization.

Well being is a multifaceted concept involving the global assessment of a person's quality of life, based on the values and expectations of each individual (Diener, 1984). The dimension of physical well-being involves subjective perceptions of health, independence, and self-efficacy. Psychological well-being is comprised of overall satisfaction with life and the dominance of positive emotional experiences over negative experiences. As indicators of the quality of life experienced, these subjective appraisals are often more meaningful to the individual than the previous emphasis on morbidity and mortality (Diener, 2000). As the "baby boomer” generation continues to mature, increasing both the number of older adults and their proportion in society, identifying ways to promote both physical and psychological well-being should become a priority.

Investigating modifiable lifestyle behaviors that potentially support and promote physical and psychological well-being, while also preventing or postponing disease and disability, is an 
important step toward increasing physical and psychological well-being in middle-age and older adulthood. (Amarantos et al., 2001; Becker \& Arnold, 2004). Referred to broadly as healthpromoting behaviors, the benefits of positive behavioral change, such as adherence to nutrition guidelines and engaging in regular physical activity, extend beyond the influence on any particular disease or risk factor to affect broad improvements across domains of functioning (Fisher et al., 2011; Michie, Abraham, Whittington, McAteer, \& Gupta, 2009). Results from the recent conclusion of a 12-year longitudinal study of middle-aged adults lend evidence of the benefits of a health-promoting lifestyle, suggesting that engaging in regular physical activity promotes an increase in current physical and psychological well-being, whereas adherence to nutritional guidelines is related to future physical and psychological well-being (Germain et al., 2013). This innovative finding accentuates the need for continued exploration into each complex relation among health-promoting behaviors, such as adherence to nutrition guidelines and engaging in regular physical activity, and physical and psychological well-being.

\section{Usual Aging}

In 1987, Rowe and Kahn presented a further distinction among non-diseased older adults by introducing the concept of usual versus successful aging. According to this model, usual aging describes individuals who are non-diseased but remain at high risk. Successful aging, then, is a more desirable state of low risk and high functioning that can be achieved through positive health behaviors (Rowe \& Kahn, 1997). This distinction is made in order to avoid the false belief that what is "usual" is inevitable. According to a life-span view of development, as the balance of gains and losses tips toward the negative with advancing age, new strategies for compensation are required in order to optimize continued functioning (Baltes, 1987). Because mid-life is the time when indicators of chronic disease and disability first begin to appear (Lachman, 2004), this 
is an optimal period for lifestyle interventions to delay, minimize, or prevent age-related changes in physical and psychological functioning.

A relatively steady decline in subjective ratings of physical health across mid-life is supported by data from the National Survey of Midlife in the United States (MIDUS), the primary source of mid-life research to date (Ryff, Keyes, \& Hughes, 2004). Failure to adjust eating behavior and level of physical activity to the body's changing need is likely responsible. Indeed, reduced muscle mass and strength, lowered respiratory capacity, and decreased bone density are all age-normative in older adults, resulting in decreased total energy requirements. Other biological mechanisms of aging, such as changes in the production of certain hormones, lead to altered sensations of thirst, hunger, and satiety, which can influence both amount and quality of overall diet, resulting in an increased prevalence of dietary deficiency (both under- and over-nourishment) in older adults (Amarantos et al., 2001; Drewnowski \& Evans, 2001; Kokkat, Dharmarajan, \& Pitchumoni, 2004).

When physical changes associated with aging disrupt previously effective guides for eating behaviors, less adaptive cues (i.e. emotional) may replace them, leading to problems with inadequate or overindulgent consumption (disordered eating; Tylka, 2006). Disordered eating has, then, been linked to poor outcomes across the life span, placing the individual at increased risk of developing psychological disorders (Patrick, Stahl, \& Sundaram, 2011). In an investigation of nutritional status and quality of life, older adults who reported multiple risk factors for malnutrition were significantly more likely to convey lower levels of physical and psychological well-being. The personal relevance of functional limitations experienced due to these diet-related factors is likely responsible (Rasheed \& Woods, 2013). 
In fact, emotion research presents a picture of increasing positive and decreasing negative affect with old age. In addition to this general trend toward positive emotion regulation, affect becomes considerably less variable by midlife (Carstensen, Pasupathi, Mayr, \& Nesselroade, 2000; Mroczek, 2004). Both men and women consistently report higher ratings for psychological health than physical health, though women's ratings tend to be lower on both of these measures than those of their male counterparts (Cleary, Zaborski, \& Ayanian, 2004; Germain et al., 2013; Kostka \& Bogus, 2007; Kvamme, Olsen, Florholmen, \& Jacobsen, 2011). A meta-analysis by Diener and Chan (2011) supports a “clear and compelling” link between subjective well-being and physical health and mortality, reinforcing the importance of public health initiatives to promote successful aging among middle-aged and older adults.

\section{Role of Health-Promoting Behaviors}

Many of the aforementioned age-normative declines are avoidable through behavioral adjustment. Health promotion efforts often focus on increasing nutrition- and physical activitybased behavior due to their amenable nature and correlational relations with numerous preventable conditions and diseases (World Health Organization [WHO], 2010). Interventions that combine adherence to nutrition guidelines and engaging in regular physical activity have the most consistent positive association with higher ratings of physical and psychological well-being for obese participants throughout each level of adulthood (Kostka \& Bogus, 2007).

There is substantial evidence that adherence to nutrition guidelines supports overall physical health and helps to prevent the development of many of the most pervasive diseases found throughout Western cultures. National guidelines for optimal nutrition are the same for all healthy adults, but may become increasingly difficult for older adults to achieve due to the aforementioned age-related declines in energy need (Drewnowski \& Evans, 2001). The Nutrition 
Committee of the American Heart Association Dietary Guidelines (2000) define an overall healthy diet as high in fruits, vegetables, and grains, and limited in foods high in saturated fats, cholesterol, and caloric density and/or low in nutritional quality, as well as alcohol and sodium Krauss et al., 2000). Wardle, Parmenter, and Waller (2000) found that greater knowledge of these dietary recommendations among 1040 adults polled was associated with higher intakes of fruit and vegetables and lower quantities of fat, independent of other factors. They also noted that women and middle-aged people scored higher on measures of nutrition knowledge than men and young adults, resulting in better adherence to nutrition guidelines reported among people of these demographic sets. Further, Rasheed and Woods (2013) found that adherence to nutrition guidelines significantly predicted outcomes in both physical and psychological well-being in older adults admitted to the hospital.

The effect of adherence to nutrition guidelines on physical and psychological well-being is further influenced by physical inactivity. Matching total energy intake to one's energy needs is essential for maintenance of a healthy body weight. In an investigation of older adults aged 6679 years, both underweight and obesity predicted increased risk of decline in physical and psychological well-being, independent of nutrition status (Kostka \& Bogus, 2007). Failures to maintain activity levels, coupled with age-related changes in nutrient need, lead many older adults to increased risk of developing cardiovascular disease and many other major health problems, including type 2 diabetes, osteoporosis, and some cancers (Krauss et al., 2000). Any resulting loss of independence can then have a potentially devastating effect on the physical and psychological well-being of older adults (Amarantos et al., 2001; Kvamme et al., 2011).

Unfortunately, older age is associated with a decrease in overall activity levels, particularly in older women (Amarantos et al., 2000; Drewnowski \& Evans, 2001). Engaging in 
regular physical activity can prevent and correct age-related loss of function through increased basal metabolism and improved muscle strength, endurance, and flexibility, contributing to increased energy requirements and supporting the continued ability to perform activities of daily living (ADLs). Strengthening exercises also improve bone health, balance, and gait, decreasing chances of fractures in frail older adults. Furthermore, adherence to the recommendation to acquire 30 minutes or more of moderate exercise five or more days per week is associated with a considerable drop in mortality, primarily through achieving and maintaining optimal body weight (Drewnowski \& Evans, 2001; Krauss et al., 2000).

In addition to the physical health benefits, physical activity has also been shown to be effective in the prevention and treatment of many common mental health problems. Following an analysis of relevant epidemiology studies, there is sufficient evidence to indicate a causal link between physical activity and reduced clinical depression across all sample characteristics (Biddle, Fox, \& Boutcher, 2000). Indices of psychological well-being are also affected by physical activity through its effects on increasing positive mood, self-esteem, cognitive agility, and sleep quality (Biddle et al., 2000). McAuley and colleagues (2000) determined that engaging in physical activity produces increased psychological well-being regardless of intensity, which can be particularly important for middle-aged and older adults.

\section{Individual Differences}

There is abundant evidence that health-promoting behaviors and physical and psychological well-being are also affected by the individual's status within the larger social structure. These determinants of health inequality stem from the social and physical environments, access to health services, and structural and societal institutions shaped by the distribution of money, power, and resources of an individual and the community and society in 
which they live. Inequalities are historically linked to discrimination or exclusion based on individual characteristics such as age, gender, race or ethnicity, socioeconomic status, sexual orientation, or disability (Centers for Disease Control and Prevention [CDC], 2014). Potentially significant individual differences may be obscured in investigations that fail to recognize the influence of social status. Investigations looking at gender differences in physical and psychological well-being, for example, often encounter an interaction among age, gender, and various well being indicators (i.e., satisfaction with life, positive/negative affect, physical functioning) that result in seemingly inconsistent outcomes (Inglehart, 2002). Social stratification is also implicated in determining participation in health-promoting behaviors (Ball, Mishra, \& Crawford, 2010). Thus, a better understanding of how social status is related to health-promoting behaviors is important for designing effective interventions.

Overall, adherence to nutrition guidelines and engaging in regular physical activity are now becoming recognized as a valuable resource for sustaining positive physical and psychological well-being through their contribution to maintaining optimal physical and psychological functioning throughout the life-span (Amarantos et al., 2000; Becker \& Arnold, 2004; Drewnowski \& Evans, 2001; Fisher et al., 2011; Germain et al., 2013; Kosta \& Bogus, 2007; McAuley et al., 2000). Age, gender, and other indicators of social status may also influence physical and psychological well-being through multiple hypothesized mechanisms relevant to the aging individual. The purpose of the current investigation is to better understand the important contribution of adherence to nutrition guidelines and engaging in regular physical activity for successful aging. Likewise, the independent contribution of sociodemographic characteristics on both the performance of these health-promoting behaviors and on the dimensions of physical and psychological well-being were explored. 


\section{Hypotheses}

[Insert Figure 1. Hypothesized Model about here]

The model depicted in Figure 1 includes available sociodemographic indicators and Nutrition and Physical Activity as predictors of Physical and Psychological Well-Being. Specific hypotheses include:

H1: We expected older age to be associated with less physical activity than middle-age (Drewnowski \& Evans, 2001).

H2: Likewise, we expected older age to be associated with poorer adherence to nutrition guidelines than middle-age (Amarantos et al., 2001; Drewnowski \& Evans, 2001; Kokkat et al., 2004).

H3: We expected to find a relation between age and physical well-being, with older adults lower than middle-aged adults (Ryff et al., 2004).

H4: However, older age was expected to be associated with greater psychological wellbeing than middle-age, due to the effects of increased positive affect (Carstensen et al., 2000; Mroczek, 2004).

H5: We expected a positive correlation between male gender and physical activity (Amarantos et al., 2000; Becker \& Arnold, 2004; Drewnowski \& Evans, 2001; Fisher et al., 2011; Germain et al., 2013; Kosta \& Bogus, 2007; McAuley et al., 2000). H6: We expected to find a positive association between female gender and adherence to nutrition guidelines (Wardle et al., 2000).

H7: We expected male gender to be more positively associated with both physical and psychological well-being than was female gender (Cleary et al., 2004; Germain et al., 2013; Kostka \& Bogus, 2007; Kvamme et al., 2011). 
H8: We expected physical activity to be positively related to physical well-being (Drewnowski \& Evans, 2001; Kosta \& Bogus, 2007; McAuley et al., 2013). H9: We also expected physical activity to be positively associated with psychological well-being (Biddle et al., 2000; McAuley et al., 2000).

H10: Adherence to nutrition guidelines was expected to positively relate to physical wellbeing (Amarantos et al., 2000; Kosta \& Bogus, 2007; Krauss et al., 2000).

H11: Adherence to nutrition guidelines was similarly expected to be positively related to psychological well-being (Amarantos et al., 2000).

H12: Level of education, work status, race or ethnicity, marital status, and income difficulty were all expected to be associated with the extent of adherence to nutrition guidelines and engaging in regular physical activity, and with levels of physical and psychological well-being, as indicators of social status (CDC, 2014), although the strength and direction of each association is exploratory.

\section{Methods}

\section{Procedure}

These data were collected as part of a larger study at West Virginia University in April, 2011. The Health Behavior and Knowledge Survey targeted adults aged 45+ years, stratified equally by race. The study consisted of extensive questionnaires to assess various aspects of health knowledge and behavior, as well as personal demographic information. Participants completed the study as a human intelligence task (HIT) through Amazon Mechanical Turk (MTurk), an online crowd-sourcing service. Research has provided evidence of both quantitative and qualitative equivalence of self-report surveys administered traditionally versus on-line (Weigold, Weigold, \& Russell, 2013). Furthermore, an evaluation by Buhrmester, Kwang, and 
Gosling (2011), suggests that MTurk samples are at least as diverse demographically as those of typical Internet samples, and are more representative than traditional, college samples. These analyses also indicate that the quality of data collected on MTurk meets or exceeds the psychometric standards found in published research $(\alpha=.73-.93$; mean $\alpha=.87$ across all scales and compensation levels; Buhrmester et al., 2011). Our participants received \$3 honoraria upon completion of the survey.

\section{Participants}

Following a pilot collection to ensure the desired demographics could be obtained online, the live study HIT was posted for seven days, yielding 587 completed surveys. Of these, 239 were excluded due to incomplete data (less than $50 \%$ of the survey completed, no demographic information, or incomplete data on key measures), reported age below the targeted range, and failed validation checks. The remaining 348 participants met the age (45+) and race (White, African American, and Hispanic American) sampling requirements.

The current study analyzes data from the 348 participants who passed all criteria for inclusion, consisting of 225 middle-aged (45-59 years; 53\% female) and 123 older adults (60-74 years; $48 \%$ female). The majority were married or partnered (62.0\%), 7.2\% were widowed, 16.1\% were divorced, and $14.7 \%$ were single/never married. A range of education levels were reported, with $15.2 \%$ having completed more than a bachelor's degree, 32.5\% holding a bachelor's degree, $12.4 \%$ holding an associate’s degree, $17.8 \%$ having completed some college or technical training, $19.8 \%$ having completed only high school or equivalent, and $2.3 \%$ having completed 11 or fewer years of education. Racial composition was 52.9\% White, 27.9\% African American, and 19.3\% Hispanic. Additional indicators of sociodemographic status exhibited similar patterns, with $50.0 \%$ of the sample employed full time, $24.1 \%$ were employed part time, 
and $25.9 \%$ of the sample were retired or unemployed. Correspondingly, 33.3\% reported having no difficulty paying bills, 31.9\% reported a little difficulty, $25.3 \%$ reported some difficulty, and 9.5\% reported having a great amount of difficulty paying bills (see Appendix A).

\section{Measures}

Health-promoting behaviors. The 52-item Health-Promoting Lifestyle Profile II (HPLP II, Walker \& Hill-Polerecky, 1996) was used to assess the frequency and type of healthpromoting behaviors in which middle-aged and older adults engaged. The HPLP II is composed of a total scale and six subscales to measure various dimensions of health promotion. Participants were asked to indicate the frequency with which they engaged in each behavior ranging from (1) “never” to (4) “routinely.” The scale is scored such that higher scores indicate more frequent engagement in health promotion. The HPLP II has demonstrated acceptable psychometric properties in previous research. The overall scale has been shown to be internally consistent $(\alpha=$ .94; Walker \& Hill-Polerecky, 1996) with alpha coefficients for the six subscales ranging from .79 to .87 (Becker \& Arnold, 2004).

The current study included two subscales from the HPLP II: Nutrition and Physical Activity. The 9-item Nutrition subscale assesses the selection and consumption of foods consistent with the daily diet guidelines provided by the USDA (e.g., "Choose a diet low in fat, saturated fat, and cholesterol”). For the Nutrition subscale, this sample reported $\mathrm{M}=23.02, \mathrm{SD}=$ 5.09, and $\alpha=.82$. The 8-item Physical Activity subscale assesses participation in light, moderate, and vigorous activity, in relation to health-promotion and to leisure/daily pursuits (e.g., "Follow a planned exercise program”). This sample reported $\mathrm{M}=18.59, \mathrm{SD}=5.51$, and $\alpha=.88$ on the Physical Activity subscale. 
Physical well-being. The Medical Outcomes Study Short Form-12 Health Survey (MOS SF-12), a valid and reliable measure of health-related quality of life, was utilized as the primary indicator of physical well-being. The SF-12 psychometrics correlate strongly with the original, full-length MOS survey while minimizing respondent burden to complete the questionnaire (Resnick \& Nahm, 2001; Ware Jr, Kosinski, \& Keller, 1996). A mixed format of responses (dichotomous, ordinal, and ratio) results in two summary scores, a Physical Component score and a Mental Component score. In the current study, we used two dimensions of the Physical Component scale as indicators of physical well-being. The Role Limitations (physical) subscale $(M=9.23, S D=10.89)$ assesses the effects of health problems on the individual's physical functioning, and is scored so that higher scores represent more limitations. The General Health subscale $(M=53.09, \mathrm{SD}=22.12)$, assesses perceptions of health, for which higher scores represent greater overall physical health.

For an additional indicator of physical well-being, we used items from the Philadelphia Geriatric Center’s Multilevel Assessment Instrument (PGC-MAI), which also assess physical well-being in older adults as a multidimensional construct. The resulting 3-item scale assesses problems performing ADLs, perception of health change, and perception of personal health compared to others' health $(\mathrm{M}=6.48, \mathrm{SD}=1.52, \alpha=.66)$. Responses are scaled for this study such that higher scores represent greater physical well-being.

Psychological well-being. The Philadelphia Geriatric Center (PGC) Positive and Negative Affect scales (Lawton, Kleban, Dean, Rajagopal, \& Parmelee, 1992) assess subjective feelings of psychological well-being. Each scale includes five items that participants must endorse on a five-point Likert scale ( 1 = "Never" to 5 = "Very Frequently") how often they experienced each emotion within the past seven days. Positive Affect includes feelings of 
"happy,” “warm-hearted,” “interested,” “content,” and “energetic” (M = 17.68, SD = 3.42, $\alpha=$ .81). Negative affect incorporates “irritated,” “sad,” “annoyed,” “worried,” and “depressed” (M $=12.71, \mathrm{SD}=4.08, \alpha=.86)$. Lawton and colleagues (1992) established that this two-factor affect structure demonstrates adequate psychometric properties and is equally applicable to all adult age groups. A single item assessing global, Subjective Happiness was used as an additional indicator of psychological well-being $(\mathrm{M}=5.05, \mathrm{SD}=1.30)$.

\section{Results}

\section{Preliminary Analyses}

Preliminary analyses establish the data were normally distributed. Mean imputation, based on that individual's responses, was used to estimate missing data points for ten cases. Means and standard deviations for all variables are presented in Table 1. Independent samples ttests (Table 1) were examined for mean differences in the measures as a function of Gender (male $=1$ and female $=2)$. Gender groups differed significantly on Physical Activity $\left(\mathrm{M}_{\text {males }}=\right.$ 19.27, $\left.\mathrm{M}_{\text {females }}=17.93, t=2.28, p=.023\right)$ and Employment Status $\left(\mathrm{M}_{\text {males }}=2.34, \mathrm{M}_{\mathrm{females}}=2.15\right.$, $t=2.05, p=.041)$.

Independent samples t-tests (Table 2) were also conducted in order to examine mean differences in the measures as a function of Age. Because Age was measured as a continuous variable, middle-age was defined as 45-59 years and older adults were defined as 60-74 years. Significant differences were found between middle-aged and older adults on Subjective Happiness $\left(\mathrm{M}_{\text {middle-aged }}=4.93, \mathrm{M}_{\text {older adults }}=5.28, t(346)=2.40 p=.017\right)$, Role Limitations subscale $\left(\mathrm{M}_{\text {middle-aged }}=8.167, \mathrm{M}_{\text {older adults }}=11.18, t(346)=2.49, p=.013\right)$, Nutrition $\left(\mathrm{M}_{\text {middle-aged }}\right.$ $\left.=22.44, \mathrm{M}_{\text {older adults }}=24.09, t(346)=2.92, p=.004\right)$, and Employment Status $\left(\mathrm{M}_{\text {middle-aged }}=2.44\right.$, $\left.\mathrm{M}_{\text {older adults }}=1.88, t(346)=-6.34, p<.001\right)$. 
Bivariate correlations were conducted in order to assess associations among variables. Table 3 presents the correlation matrix, reporting Pearson's coefficients for continuous variables and Spearman's rho for categorical variables. Indices of physical and psychological well-being were inspected, revealing highly significant $(p<.01)$ relations among indicators of each latent construct (physical and psychological well-being).

[Insert Table 3 about here]

In order to determine the most parsimonious combination of sociodemographic characteristics to include in the model, multiple statistical tests were analyzed. Bivariate correlations revealed only small associations between race or marital status and any other variable in the model (see Table 3). Analysis of variance (ANOVA) and regression analyses indicated a lack of unique variance accounted for by either of these variables. Thus, race and marital status were eliminated from further analyses.

\section{Testing the Model}

In order to assess the influence of health-promoting behaviors on physical and psychological well-being, variables were entered into a mixed structural equation model (SEM), with Nutrition and Physical Activity behaviors as predictors of Physical and Psychological WellBeing. Age, gender, and indicators of Education Level, Employment Status, and Income Difficulty were also tested as possible predictors of engagement in health-promoting behaviors and as contributors to Physical and Psychological Well-Being.

The AMoS program was used to estimate path models using variance-covariance matrices. All hypothesized paths are tested simultaneously. Standardized maximum likelihood estimates (MLE) were tested for statistical significance, using the Critical Ratio (CR = 
MLE/Standard Error of the MLE). CRs greater than 1.96 are interpreted as significant at the $p<$ .05 level (Arbuckle, 1995; Byrne, 2010). As shown in the upper portion of Table 4, the measured indicators loaded onto the latent constructs as expected. Recommended model modifications are also supplied to improve the model fit, but logic and theory must guide in their application. Fewer covarying indicators, in this instance, allows for more specific references. -Insert Table 4 about here

When assessing the model, good fit to the data is indicated by a non-significant Chisquare $(p<.05)$. However, when sample size is large, the Chi-square statistic is sensitive to small departures between models. Thus, multiple indices of fit were assessed in order to evaluate the fit of the structural model, including the Chi-square, the Tucker-Lewis Index (TLI), the Goodness of Fit Index (GFI), and the Root Mean Square Error Approximation (RMSEA). Good model fit was indicated if the values for the TLI and the GFI were greater than .90. Further, indication of adequate fit was indicated when RMSEA values were less than .08 and was considered a good fit when values were less than .05 (Byrne, 2010). These summary statistics suggested a good fit of the model to the data $\left(\mathrm{x}^{2}(\mathrm{df}=45, \mathrm{~N}=348)=130.62, p<.001\right.$; TLI $=$ .864 ; GFI = .948; RMSEA = .074). The model accounts for $40.4 \%$ of the variance in physical well-being and for $26.3 \%$ of variance in psychological well-being.

Each hypothesized path was also assessed for significance. Results are shown in the bottom portion of Table 4. Notably, male Gender $(\beta=.107)$, Physical Activity $(\beta=.409)$, Education Level $(\beta=.155)$, Employment Status $(\beta=.133)$, and Income Difficulty $(\beta=-.165)$ were all significantly associated with better Physical Well-Being. Adherence to Nutrition guidelines $(\beta=.207)$, engaging in Physical Activity $(\beta=.175)$, and Income Difficulty $(\beta=-.281)$ were all related to greater Psychological Well-Being. Age $(\beta=.146)$, Education Level $(\beta=.313)$, 
and Income Difficulty ( $\beta=$-.182) were all significantly associated with better adherence to Nutrition guidelines. Education level $(\beta=.273)$, Employment Status $(\beta=.140)$, and Income Difficulty ( $\beta=-.118$ ) were all significantly related to more Physical Activity.

Although the model fit well, several non-significant paths were included. In order to identify the most parsimonious model, we conducted exploratory post-hoc analyses. Model revisions consisted of dropping the non-significant paths one at a time and re-evaluating the fit of the data to the model (see Appendix B). Dropping all non-significant paths did not significantly improve fit or amount of variance accounted for in the model $\left(\mathrm{x}^{2}(\mathrm{df}=54, n=348)=149.149, p\right.$ $<.001 ; \mathrm{TLI}=.874 ; \mathrm{GFI}=.940 ; \mathrm{RMSEA}=.071 ; \mathrm{r}^{2}$ physical well-being $\left.=23.7 \%\right), \mathrm{r}^{2}$ psychological well-being $=$ $41.2 \%$.

Although cross-sectional analyses limit assumptions of causality, logic and theory indicate reciprocal relations. In order to rule out opposite-direction effects, we contrasted two exploratory SEM models, one with the direction of effects as hypothesized $\left(\mathrm{x}^{2}(\mathrm{df}=17, n=348)\right.$ $=55.183, p<.001 ; \mathrm{TLI}=.925 ; \mathrm{GFI}=.966 ; \mathrm{RMSEA}=.079)$ and one in which we reversed the direction of effects $\mathrm{x}^{2}(\mathrm{df}=18, n=348)=152.002, p<.001 ; \mathrm{TLI}=.752 ; \mathrm{GFI}=.904 ; \mathrm{RMSEA}=$ $.143)$. Comparing the two models $\left(\mathrm{x}^{2}(\mathrm{df}=1, n=348)=96.819, p<.001\right)$ revealed the hypothesized model as a significantly better fit to the data.

\section{Discussion}

This study examined the relations among adherence to nutrition guidelines and engaging in regular physical activity, and physical and psychological well-being. Specifically, the current investigation serves to illuminate the ways in which adherence to nutrition guidelines and engaging in regular physical activity relate to the dimensions of physical and psychological wellbeing differentially. Although many significant associations were found in these analyses, the 
size of these effects is small. Considered together, however, the model presented provides a great deal of information. The complete model accounted for $40.4 \%$ of the variance in physical wellbeing and $26.3 \%$ of the variance in psychological well-being. These results represent a large amount of variance explained in the context of health promotion, by targeting only two behaviors. Our findings add to the growing literature exploring the complex pathways, factors, and mechanisms involved in the relations among adherence to nutrition guidelines and engaging in regular physical activity as they relate to physical and psychological well-being.

The primary hypotheses, wherein adherence to nutrition guidelines and engaging in physical activity relate to increased physical and psychological well-being were supported, with the exception of the relation between adherence to nutrition guidelines and physical well-being. This lack of a significant relation where logic and theory suggest a relation should exist may be indicative of the specific, long-term relation between these variables discovered in longitudinal data (Germain et al., 2013). Additionally, examination of the remaining paths of influence within the model serve to further our understanding of these primary relations.

A significant effect of age on adherence to nutrition guidelines was supported by the model, but in the opposite direction than was hypothesized, with older adults scoring higher on this variable than middle-aged adults. Engaging in regular physical activity was not significantly related to age, nor was age associated directly with physical or psychological well-being in the model. Although previous literature suggests that older adults are less likely to achieve nutrition guidelines and regular physical activity than are middle-aged adults, the current sample had a relatively young cut-off between these two groups (60 years) and contained only young-old ( $\leq 74$ years) adults, which could be concealing real age-associated differences in late life. Also, these relatively young middle-aged adults may not yet be experiencing health issues that often prompt 
engagement in health-promoting behaviors. However, recent evidence has emerged to indicate that mid-life is a critical period for establishing health-promoting behaviors for successful aging (Lachman, 2004).

The investigation of gender in our model supports some previous literature, with males in our sample reporting significantly more physical activity than females. Contrary to expectations, we did not, however, find an effect of gender on adherence to nutrition guidelines. This result may indicate that married individuals (62\% of our sample) are eating better together than they may if single or widowed. Gender was not significantly associated with psychological wellbeing, but was significantly associated with higher levels of physical well-being. Contrary to our hypothesis, however, it was females that reported better physical health in this model. These equivocal outcomes underscore the complexity of variables affecting physical and psychological well-being. The heterogeneity found among middle-aged and older adults emphasizes the importance of parsing out each relation.

\section{Implications}

This study is one of few to date to investigate the relation of adherence to nutrition guidelines and engaging in regular physical activity with physical and psychological well-being in middle-aged and older adults. Accruing evidence supporting the influence of behavior on quality of life is the first step in developing effective interventions for improving physical and psychological well-being in old age. Furthermore, middle-age remains a relatively ignored period in the study of life-span development. However, this is the time in the life-span when many age-related declines become salient (Lachman, 2004), rendering these adults the most likely target of future health-promotion campaigns. Discovering characteristics specific to these 
adults will advance our ability to successfully alter the aging trajectories of future generations of older adults.

Another important aspect of this study is the use of the internet for data collection. This method of data collection has several potential benefits for the researcher, including reducing the costs and time involved in data collection and access to larger, more diverse samples, especially historically hard-to-reach populations. Online surveys are also user-friendly and convenient for participants. Potential problems include selection bias, limiting samples to only those with Internet access, and loss of clarification due to the lack of contact with the researcher. As on-line data collection has increased in popularity, many questions regarding data equivalence have, therefore, been raised. Recent analysis indicates both quantitative and qualitative equivalence of paper-and-pencil and Internet data collection methods. The differences found in auxiliary equivalence (missing data and completion time) were not significantly different by collection method. These results confirm several earlier investigations that most self-report surveys used in social sciences can successfully transition from traditional methods to the Internet without compromising quality (Weigold et al., 2013).

\section{Limitations and Future Directions}

Although this study has both theoretical and practical significance, there are several limitations to be considered when interpreting these data. First, these data were based solely on self-reported dietary and physical activity behaviors. Self-report data has several intrinsic benefits and some note-worthy disadvantages. Benefits include easy, inexpensive collection and anonymity. The most common disadvantages are response biases, wherein the participants’ responses are affected by social desirability and expectations, and cognitive fatigue and memory 
burden, affecting the validity of their responses (Paulhas \& Vazire, 2007; Schwarz, 1999). The current study was designed to reduce these effects while optimizing efficiency of data collection.

As a snap-shot of a dynamic process, due to the cross-sectional nature of the data, we cannot declare unequivocally that the hypothesized direction of influence is appropriate. Physical and psychological well-being may be an important antecedent to engaging in health-promoting behaviors, rather than the other way around. However, our post-hoc SEM adds some credibility to the hypothesized direction of influence. More likely, these relations are reciprocally related. Longitudinal studies are needed in order to disentangle the cause and effect relationships between lifestyle and physical and psychological well-being, and how these relations evolve over time. Cross-sectional evaluations of subjective well-being are, however, a valid representation of an individual's current state of functioning within their current environment (Diener, 2000).

It was of further interest in this study to determine what influence age, gender, and sociodemographic characteristics exerted on the other variables in the model. Originally, these additional factors included race, marital status, education level, employment status, and income difficulty. Following exploratory analyses, race and marital status were eliminated due to inconsistent outcomes. The remaining sociodemographic characteristics (education level, employment status, and income difficulty) are often used to indicate socioeconomic status. However, this study did not have enough power to support another latent variable in the model. Also, these social variables were poorly measured in this data set, decreasing variability within and increasing confounding between them, limiting assumptions. Interestingly, sociodemographic indicators evidenced significant influence within the model, exemplifying the necessity of considering the influence of the social and physical environment in every investigation. Furthermore, there is not a lot of research on the relations between social status 
and adherence to nutrition guidelines and engaging in regular physical activity in lifespan psychology, so the addition of these factors in our model adds to the knowledge base.

\section{Conclusion}

Although there are vast literatures exploring correlates of health-promotion and of wellbeing, little research has directly measured the associations between the two. The present findings suggest that adherence to nutrition guidelines and engaging in regular physical activity are each differentially associated with greater physical and psychological well-being. Further, the inclusion of age, gender, and several indicators of social status considerably increased the amount of variance explained in the model. This strongly indicates the need to accurately measure and include sociodemographic indicators in all future research. Because cross-sectional data limit our ability to establish causation among variables, longitudinal designs are needed to further parse the specific underlying mechanisms involved in these complex relations. Further identification of factors involved in and mechanisms regulating these relations will, then, allow for the advancement of effective lifestyle-change techniques to improve the well being trajectories of a growing middle-aged and older adult population.

Given that people can now expect to live longer than ever before in history (Amarantos et al., 2001; Drewnowski \& Evans, 2001), ensuring continued physical and psychological wellbeing through the end of life has to become a priority. Identifying the mechanisms through which we can increase well being in the aging population is the first step toward achieving this goal. Adherence to nutrition guidelines and engaging in regular physical activity represent some of the most effective modifiable lifestyle factors for increasing physical and psychological well-being (WHO, 2010). Additionally, interventions based on theory have proven to have the largest effect on the intended behaviors (Michie et al, 2009). Thus, designing interventions that increase 
knowledge of (Wardle et al., 2000) and participation in these two health-promoting behaviors has the potential to support successful aging and increase physical and psychological well-being throughout the population. Future research should seek to illuminate additional positive health behaviors associated with increased physical and psychological well-being among middle-aged and older adults. 


\section{References}

Amarantos, E., Martinez, A., \& Dwyer, J. (2001). Nutrition and quality of life in older adults. Journals of Gerontology: SERIES A, 56A, 54-64.

Arbuckle, J. (1995). AMOS: Analysis of moment structures user's guide. Small Waters: Chicago.

Ball, K., Mishra, G. D., \& Crawford, D. (2003). Social factors and obesity: An investigation of the role of health behaviours. International Journal of Obesity, 27(3), 394-403.

Baltes, P. (1987). Theoretical propositions of life-span developmental psychology: On the dynamics between growth and decline. Developmental Psychology, 23(5), 611-626.

Becker, C.M. \& Arnold, W. (2004). Health promoting behaviors of older Americans versus young and middle-aged adults. Educational Gerontology, 30, 835-844.

Biddle, S. J. H., Fox, K. R., \& Boutcher, S. H. (Eds.). (2000). Physical activity and psychological well-being. Routledge: London and New York.

Buhrmester, M., Kwang, T., \& Gosling, S. D. (2011). Amazon's Mechanical Turk: A new source of inexpensive, yet high-quality, data? Perspectives on Psychological Science, 6(1), 3-5.

Byrne, B. M. (2010). Structural Equation Modeling with AMOS, $2^{\text {nd }}$ Ed. New York: Routledge. Carstensen, L.L., Pasupathi, M., Mayr, U., \& Nesselroade, J.R. (2000). Emotional experience in everyday life across the adult life span. Journal of Personality and Social Psychology, 79(4), 644-655. doi: 10.1037/0022-3514.79.4.644

Centers for Disease Control and Prevention. (2014). Social determinants of health. Retrieved from http://www.cdc.gov/socialdeterminants/definitions.html

Cleary, P. D., Zaborski, L.B., \& Ayanian, J.Z. (2004). Sex differences in health over the course of midlife. In O.G. Brim, C.D. Ryff, \& R. C. Kessler (Eds.), How healthy are we? A 
national study of well-being at midlife (pp. 205-226). Chicago, IL: The University of Chicago Press.

Diener, E. (1984). Subjective well-being. Psychological Bulletin, 95(3), 542-575.

Diener, E. (2000). Subjective well-being: The science of happiness and a proposal for a national index. American Psychologist, 55(1), 34-43. doi: 10.1037//0003-066x.55.1.34

Diener, E. \& Chan, M. Y. (2011). Happy people live longer: Subjective well-being contributes to health and longevity. Applied Psychology: Health and Well-Being, 3(1), 1-43. doi:10.1111/j.1758-0854.2010.01045.x

Drewnowski, A. \& Evans, W.J. (2001). Nutrition, physical activity, and quality of life in older adults: Summary. Journals of Gerontology: SERIES A, 56A, 89-94.

Fisher, E. B., Fitzgibbon, M.L., Glasgow, R. E., Haire-Joshu, D., Hayman, L.L., Kaplan, R. M., Nanney, M. S., \& Ockene, J.K. (2011). Behavior matters. American Journal of Preventive Medicine, 40(5), e15-e30. doi: 10.1016/j.amepre.2010.12.031

Germain, L., Latarche, C., Kesse-Guyot, E., Galan, P., Hercberg, S., \& Briancon, S. (2013). Does compliance with nutrition guidelines lead to healthy aging? A quality-of-life approach. Journal of the Academy of Nutrition and Dietetics 113(2), 228-240.

Inglehart, R. (2002). Gender, aging, and subjective well-being. International Journal of Comparative Sociology, 43(3-5), 391-409.

Kokkat, A. J., Dharmarajan, T.S., \& Pitchumoni, C.S. (2004). Nutrition in older adults. Practical Gastroenterology, 28(6), 22-44.

Kostka, T. \& Bogus, K. (2007). Independent contribution of overweight/obesity and physical activity to lower health-related quality of life in community-dwelling older subjects. Zeitschrift für Gerontologie und Geriatrie, 40, 43-51. doi: 10.1007/s00391-006-0374-6 
Krauss, R.M., Eckel, R.H., Howard, B., Appel, L.J., Danials, S.R., Deckelbaum, R.J., Erdman, J.W., Kris-Etherton, P., Goldberg, I.J., Kotchen, T.A., Lichtenstein, A.H., Mitch, W.E., Mullis, R., Robinson, K., Wylie-Rosett, J., St. Jeor, S., Suttie, J., Tribble, D.L., \& Bazzarre, T.L. (2000). AHA dietary guidelines revision 2000: A statement for healthcare professionals from the nutrition committee of the American Heart Association. Circulation, 102(18), 2284-2299.

Kvamme, J.M., Olsen, J. A., Florholmen, J., \& Jacobsen, B. K. (2011). Risk of malnutrition and health-related quality of life in community-living elderly men and women: The Tromso study. Quality of Life Research, 20, 575-582 doi: 10.1007/s11136-010-9788-0

Lachman, M. E. (2004). Development in midlife. Annual Review of Psychology, 55, 305-331.

Lawton, M.P., Kleban, M. H., Dean, J., Rajagopal, D., \& Parmelee, P. A. (1992). The factorial generality of brief positive and negative affect measures. Journal of Gerontology: Psychological Sciences, 47, 228-237.

McAuley, E., Blissmer, B., Marquez, D. X., Jerome, G. J., Kramer, A. F., \& Katula, J. (2000). Social relations, physical activity, and well being in older adults. Preventive Medicine, 31, 608-617.

Michie, S., Abraham, C., Whittington, C., McAteer, J., \& Gupta, S. (2009). Effective techniques in healthy eating and physical activity interventions: A meta-regression. Health Psychology, 28(6), 690-701.

Mroczek, D. K. (2004). Positive and Negative Affect at Midlife. In O.G. Brim, C.D. Ryff, \& R. C. Kessler (Eds.), How healthy are we? A national study of well-being at midlife (pp. 205-226). Chicago, IL: The University of Chicago Press. 
Patrick, J.H., Stahl, S.T., \& Sundaram, M. (2011). Disordered eating and psychological distress among adults. International Journal of Aging and Human Development, 73(3), 209-226.

Paulhus, D. L. \& Vazire, S. (2007). The self-report method. In Robins, R. W., Fraley, R. C., \& Krueger, R. F. (Eds.), Handbook of research methods in personality psychology (224239). New York: Guilford.

Rasheed, S. \& Woods, R. T. (2013). An investigation into the association between nutritional status and quality of life in older people admitted to hospital. Journal of Human Nutrition and Dietetics. Advance online publication. doi:10.1111/jhn/2072

Resnick, B. \& Nahm, E. S. (2001). Reliability and validity testing of the revised 12-item ShortForm Health Survey in older adults. Journal of Nursing Measurement, 9(2), 151-161.

Rowe, J. W. \& Kahn, R. L. (1987). Human aging: Usual and successful. Science, 237(4811), 143-149.

Rowe, J. W. \& Kahn, R. L. (1997). Successful aging. The Gerontologist, 37(4), 433-440.

Ryff, C.D., Keyes, C.L.M., \& Hughes, D.L. (2004). Psychological well-being in MIDUS: Profiles of ethnic diversity and life-course uniformity. In O.G. Brim, C.D. Ryff, \& R. C. Kessler (Eds.), How healthy are we? A national study of well-being at midlife (pp. 205226). Chicago: The University of Chicago Press.

Schwartz, N. (1999). Self-reports: How the questions shape the answers. American Psychologist, 54(2), 93-105.

Tylka, T. L. (2006). Development and psychometric evaluation of a measure of intuitive eating. Journal of Counseling Psychology, 53(2), 226-240.

Walker, S.N. \& Hill-Polerecky, D. M. (1996). Psychometric evaluation of the Health-Promoting Lifestyle Profile II. Unpublished manuscript, University of Nebraska Medical Center. 
Wardle, J., Parmenter, K., \& Waller, J. (2000). Nutrition knowledge and food intake. Appetite, 34, 269-275.

Ware Jr, J. E., Kosinski, M., \& Keller, S. D. (1996). A 12-Item Short-Form Health Survey: construction of scales and preliminary tests of reliability and validity. Medical Care, 34(3), 220-233.

Weigold, A., Weigold, I. K., \& Russell, E. J. (2013). Examination of the equivalence of selfreport survey-based paper-and-pencil and Internet data collection methods. Psychological Methods, 18(1), 53-70.

World Health Organization. (1948). World Health Organization constitution. In Basic documents. Geneva: Author.

World Health Organization. (2010). Global recommendations on physical activity for health. Geneva: World Health Organization, 8-10. 
Table 1

Means and Standard Deviations for Key Variables and for Key Variables by Gender

\begin{tabular}{|c|c|c|c|c|c|c|c|c|}
\hline \multirow[t]{3}{*}{ Variable } & \multirow[b]{3}{*}{$M$} & \multirow[t]{2}{*}{ Sample } & \multicolumn{4}{|c|}{ Gender } & \multirow[b]{3}{*}{$t$} & \multirow[b]{3}{*}{$r$} \\
\hline & & & \multicolumn{2}{|c|}{$\begin{array}{l}\text { Male } \\
(N=170)\end{array}$} & \multicolumn{2}{|c|}{$\begin{array}{l}\text { Female } \\
(N=178)\end{array}$} & & \\
\hline & & $S D$ & $M$ & $S D$ & $M$ & $S D$ & & \\
\hline \multicolumn{9}{|l|}{ Psychological WB } \\
\hline Positive Affect & 17.68 & 3.42 & 17.43 & 3.37 & 17.91 & 3.46 & -1.31 & .07 \\
\hline Negative Affect & 12.71 & 4.08 & 12.56 & 4.24 & 12.85 & 3.93 & -.66 & .04 \\
\hline Subjective Happy & 5.05 & 1.30 & 4.98 & 1.34 & 5.12 & 1.26 & -.97 & .05 \\
\hline \multicolumn{9}{|l|}{ Physical WB } \\
\hline General Health & 53.09 & 22.12 & 52.79 & 22.50 & 53.37 & 21.81 & -.24 & .01 \\
\hline Role Limitations & 9.23 & 10.89 & 9.56 & 10.56 & 8.92 & 11.21 & .55 & .03 \\
\hline MAI 3-item scale & 6.48 & 1.52 & 5.77 & .98 & 5.82 & .99 & -.53 & .03 \\
\hline Physical Activity & 18.59 & 5.51 & 19.27 & 5.40 & 17.93 & 5.56 & $2.28 *$ & .12 \\
\hline Nutrition & 23.02 & 5.09 & 22.91 & 4.74 & 23.13 & 5.42 & -.42 & .02 \\
\hline Education Level & 3.99 & 1.46 & 4.02 & 1.44 & 3.95 & 1.48 & .47 & .02 \\
\hline Employment Status & 2.24 & .84 & 2.34 & .83 & 2.15 & .84 & $2.05 *$ & .11 \\
\hline Income Difficulty & 1.11 & .98 & 1.03 & .99 & 1.19 & .97 & -1.49 & .08 \\
\hline
\end{tabular}

Note. $\mathrm{MAI}=$ Multilevel Assessment Instrument; $\mathrm{WB}=$ Well Being. ${ }^{*} p<.05 .{ }^{* *} p<.01$ 
Table 2

Means and Standard Deviations for Key Variables and for Key Variables by Age Group

\begin{tabular}{|c|c|c|c|c|c|c|c|c|}
\hline \multirow[t]{3}{*}{ Variable } & \multicolumn{2}{|c|}{ Sample } & \multicolumn{4}{|c|}{ Age Group } & \multirow[b]{3}{*}{$t$} & \multirow[b]{3}{*}{$r$} \\
\hline & \multirow[b]{2}{*}{$M$} & \multirow[b]{2}{*}{$S D$} & \multicolumn{2}{|c|}{$\begin{array}{l}\text { Middle-age } \\
(\mathrm{N}=255)\end{array}$} & \multicolumn{2}{|c|}{$\begin{array}{l}\text { Older } \\
(\mathrm{N}=123)\end{array}$} & & \\
\hline & & & $M$ & $S D$ & $M$ & $S D$ & & \\
\hline \multicolumn{9}{|l|}{ Psychological WB } \\
\hline Positive Affect & 17.68 & 3.42 & 17.71 & 3.36 & 17.62 & 3.55 & -.23 & .01 \\
\hline Negative Affect & 12.71 & 4.08 & 12.74 & 4.25 & 12.64 & 3.77 & -.22 & .01 \\
\hline Subjective Happy & 5.05 & 1.30 & 4.93 & 1.29 & 5.280 & 1.28 & $2.40 *$ & .13 \\
\hline \multicolumn{9}{|l|}{ Physical WB } \\
\hline General Health & 53.09 & 22.12 & 54.11 & 21.32 & 51.22 & 23.49 & -1.17 & .06 \\
\hline Role Limitations & 9.23 & 10.89 & 8.17 & 10.79 & 11.18 & 10.83 & $2.49 *$ & .13 \\
\hline MAI 3-item scale & 6.48 & 1.52 & 5.75 & 1.00 & 5.87 & .95 & 1.08 & .06 \\
\hline Physical Activity & 18.59 & 5.51 & 18.32 & 5.37 & 19.07 & 5.76 & 1.22 & .07 \\
\hline Nutrition & 23.02 & 5.09 & 22.44 & 5.07 & 24.09 & 4.99 & $2.92 * *$ & .16 \\
\hline Education Level & 3.99 & 1.46 & 4.06 & 1.37 & 3.85 & 1.60 & -1.25 & .07 \\
\hline Employment Status & 2.24 & .84 & 2.44 & .77 & 1.88 & .84 & $-6.34 * *$ & .33 \\
\hline Income Difficulty & 1.11 & .98 & 1.13 & .98 & 1.07 & .97 & -.62 & .03 \\
\hline
\end{tabular}

Note. $\mathrm{MAI}=$ Multilevel Assessment Instrument; $\mathrm{WB}=$ Well Being. ${ }^{*} p<.05 .{ }^{* *} p<.01$ 
Table 3

Bivariate Associations among Variables

\begin{tabular}{|c|c|c|c|c|c|c|c|c|c|c|c|c|c|c|}
\hline Variable & 1 & 2 & 3 & 4 & 5 & 6 & 7 & 8 & 9 & 10 & 11 & 12 & 13 & 14 \\
\hline \multicolumn{15}{|l|}{ 1.Positive Affect } \\
\hline 2.Negative Affect & $-.56 * *$ & & & & & & & & & & & & & \\
\hline 3.Subjective Happy & $.65 * *$ & $-.51 * *$ & & & & & & & & & & & & \\
\hline 4.General Health & $.33^{* *}$ & $-.23 * *$ & $.38 * *$ & & & & & & & & & & & \\
\hline 5.Role Limitations & $-.19 * *$ & $.16 * *$ & $-.22 * *$ & $-.50 * *$ & & & & & & & & & & \\
\hline 6.MAI 3-item scale & $.23 * *$ & $-.15 * *$ & $.27 * *$ & $.32 * *$ & $-.17 * *$ & & & & & & & & & \\
\hline 7.Physical Activity & $.28 * *$ & $-.19 * *$ & $.32 * *$ & $.46^{* *}$ & $-.28 * *$ & $.31 * *$ & & & & & & & & \\
\hline 8.Nutrition & $.33 * *$ & $-.19 * *$ & $.32 * *$ & $.36 * *$ & $-.23 * *$ & $.30 * *$ & $.65^{* *}$ & & & & & & & \\
\hline 9.Age & -.01 & -.05 & $.14^{* *}$ & -.03 & $.13^{*}$ & .09 & .02 & $.14^{* *}$ & & & & & & \\
\hline 10.Gender & .06 & .03 & .05 & .01 & -.04 & .02 & -.12 & .03 & -.03 & & & & & \\
\hline 11.Race & $-.13^{*}$ & .09 & -.06 & -.10 & .00 & -.10 & -.00 & -.04 & -.15 & -.07 & & & & \\
\hline 12.Marital Status & $-.20 * *$ & .08 & $-.29 * *$ & $-.13 * *$ & .07 & -.09 & $-.12 *$ & -.14 & -.06 & -.02 & $.04 *$ & & & \\
\hline 13.Education Level & $.16^{* *}$ & .04 & $.14^{* *}$ & $.25 * *$ & $-.29 * *$ & $.14 * *$ & $.30 * *$ & $.33^{* *}$ & $-.06 * *$ & -.02 & $-.08 *$ & $-.14 * *$ & & \\
\hline 14.Employment Status & $.12 *$ & -.09 & .09 & $.18 * *$ & $-.26 * *$ & .03 & $.16 * *$ & $-.01 * *$ & -.31 & -.12 & .09 & -.07 & $.14^{* *}$ & \\
\hline 15.Income Difficulty & $-.20 * *$ & $.27 * *$ & $-.33 * *$ & $-.23 * *$ & $.22 * *$ & $.11^{*}$ & $-.20 * *$ & $-.23 * *$ & $-.05 *$ & $.09 * *$ & .06 & .27 & $-.15 * *$ & -.23 \\
\hline
\end{tabular}

Note. $\mathrm{MAI}=$ Multilevel Assessment Instrument. ${ }^{*} p<0.05,{ }^{* *} p<0.01$ 
Table 4

Standardized and Unstandardized Estimates for Model

\begin{tabular}{|c|c|c|c|c|}
\hline Variable & $\beta$ & $b$ & $\mathrm{SE}(b)$ & $\mathrm{CR}$ \\
\hline \multicolumn{5}{|l|}{ Measurement Model } \\
\hline Positive Affect $\leftarrow$ Psychological WB & .807 & 2.646 & .203 & $13.04 * * *$ \\
\hline Negative Affect $\leftarrow$ Psychological WB & -.660 & -2.579 & .225 & $-11.46^{* * *}$ \\
\hline Subjective Happy $\leftarrow$ Psychological WB & .804 & & & \\
\hline General Health $\leftarrow$ Physical WB & .796 & & & \\
\hline Role Limitations $\leftarrow$ Physical WB & -.599 & -.372 & .044 & $-8.36 * * *$ \\
\hline MAI 3-item scale $\leftarrow$ Physical WB & .389 & .022 & .004 & $6.00^{* * *}$ \\
\hline \multicolumn{5}{|l|}{ Structural Model } \\
\hline Physical Activity $\leftarrow$ Age & .078 & .007 & .005 & 1.44 \\
\hline Nutrition $\leftarrow$ Age & .146 & .010 & .004 & $2.73^{* *}$ \\
\hline Psychological WB $\leftarrow$ Age & .065 & .009 & .008 & 1.13 \\
\hline Physical WB $\leftarrow$ Age & -.023 & -.052 & .130 & -.40 \\
\hline Physical Activity $\leftarrow$ Gender & -.090 & -.122 & .068 & -1.78 \\
\hline Nutrition $\leftarrow$ Gender & .046 & .052 & .056 & .93 \\
\hline Psychological WB $\leftarrow$ Gender & .102 & .212 & .112 & 1.90 \\
\hline Physical WB $\leftarrow$ Gender & .107 & 3.740 & 1.905 & $1.96 *$ \\
\hline Physical Activity $\leftarrow$ Education Level & .273 & .128 & .024 & $5.43^{* * *}$ \\
\hline Nutrition $\leftarrow$ Education Level & .313 & .121 & .019 & $6.35^{* * *}$ \\
\hline Psychological WB $\leftarrow$ Education Level & -.040 & -.028 & .040 & -.71 \\
\hline Physical WB $\leftarrow$ Education Level & .155 & 1.863 & .687 & $2.71^{* *}$ \\
\hline Physical Activity $\leftarrow$ Employment Status & .140 & .113 & .046 & $2.48^{*}$ \\
\hline Nutrition $\leftarrow$ Employment Status & -.021 & -.014 & .037 & -.38 \\
\hline Psychological WB $\leftarrow$ Employment Status & .077 & .096 & .075 & 1.29 \\
\hline Physical WB $\leftarrow$ Employment Status & .133 & 2.761 & 1.275 & $2.16^{*}$ \\
\hline Physical Activity $\leftarrow$ Income Difficulty & -.118 & -.082 & .037 & $-2.25^{*}$ \\
\hline Nutrition $\leftarrow$ Income Difficulty & -.182 & -.105 & .030 & $-3.53 * * *$ \\
\hline Psychological WB $\leftarrow$ Income Difficulty & -.281 & -.300 & .061 & $-4.93 * * *$ \\
\hline Physical WB $\leftarrow$ Income Difficulty & -.165 & -2.950 & 1.023 & $-2.88 * *$ \\
\hline Psychological WB $\leftarrow$ Physical Activity & .175 & .268 & .110 & $2.43^{*}$ \\
\hline Physical WB $\leftarrow$ Physical Activity & .409 & 10.486 & 1.908 & $5.50 * * *$ \\
\hline Psychological WB $\leftarrow$ Nutrition & .207 & .384 & .136 & $2.82 * *$ \\
\hline Physical WB $\leftarrow$ Nutrition & .102 & 3.163 & 2.315 & 1.37 \\
\hline Nutrition $\longleftrightarrow$ Physical Activity & .621 & .205 & .021 & $9.83^{* * *}$ \\
\hline Employment Status $\longleftrightarrow$ Age & -.367 & -2.431 & .367 & $-6.63 * * *$ \\
\hline Employment Status $\longleftrightarrow$ Income Difficulty & -.264 & -.216 & .043 & $-5.08 * * *$ \\
\hline
\end{tabular}

Note. MAI = Multilevel Assessment Instrument; WB = Well Being. $\mathrm{x}^{2}(\mathrm{df}=45, \mathrm{~N}=348)=130.62, \mathrm{p}=.001$;

TLI = .864; GFI = .948; RMSEA = .074.). Physical well-being $\left(r^{2}=.40\right)$; Psychological well-being $\left(r^{2}=.26\right)$. ${ }^{*} p<.05 .{ }^{* *} p<.01 .{ }^{* * *} p<.001$ 


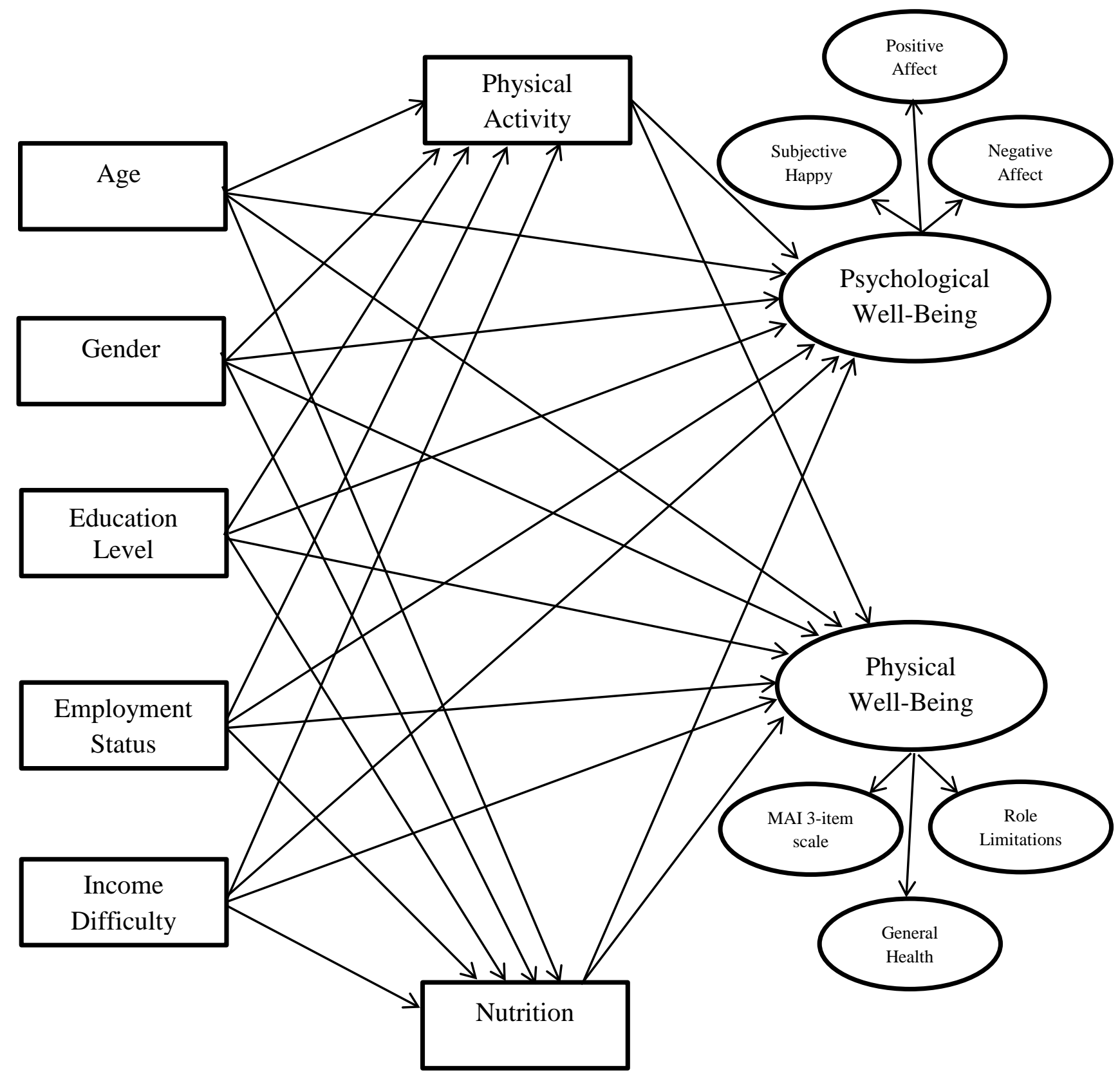

Figure 1. Hypothesized Model. This figure represents each hypothesized relation between variables. 


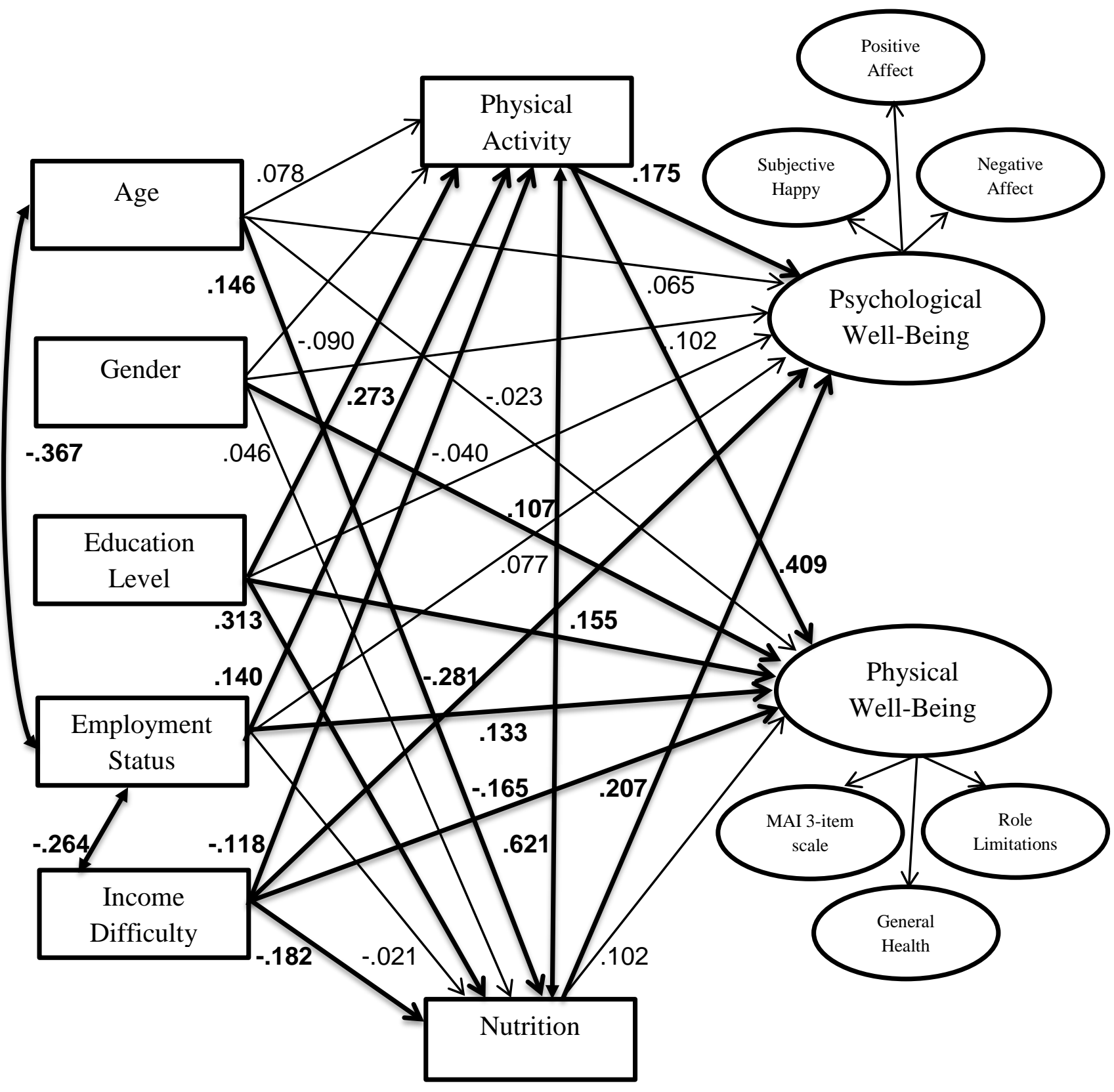

Figure 2. Final Model. This structural model shows each tested path with covariance and beta weights. Bold paths indicate significance. 
Appendix A

Descriptive Statistics for Demographic Variables

\begin{tabular}{|c|c|c|c|}
\hline Variable & $\mathrm{N}$ & $\%$ & $\mathrm{M}(\mathrm{SD})$ \\
\hline Age & & & $54.41(7.89)$ \\
\hline Middle-aged & 225 & 64.7 & \\
\hline Older & 123 & 35.3 & \\
\hline Gender & & & $1.51(.50)$ \\
\hline Male & 170 & 48.9 & \\
\hline Female & 178 & 51.1 & \\
\hline Race & & & $1.66(.78)$ \\
\hline White & 184 & 52.9 & \\
\hline African American & 97 & 27.9 & \\
\hline Hispanic & 67 & 19.3 & \\
\hline Marital Status & & & $1.99(1.30)$ \\
\hline Married/Partnered & 216 & 62.0 & \\
\hline Widowed & 25 & 7.2 & \\
\hline Divorced & 56 & 16.1 & \\
\hline Single/Never Married & 51 & 14.7 & \\
\hline Education Level & & & $3.99(1.46)$ \\
\hline 11 or Fewer Years & 8 & 2.3 & \\
\hline High school/GED & 69 & 19.8 & \\
\hline Some College or Technical Training & 62 & 17.8 & \\
\hline Associates & 43 & 12.4 & \\
\hline Bachelors & 113 & 32.5 & \\
\hline More Than Bachelors & 53 & 15.2 & \\
\hline Employment status & & & $2.24(.84)$ \\
\hline Retired/Unemployed & 90 & 25.9 & \\
\hline Employed, Part Time & 84 & 24.1 & \\
\hline Employed, Full time & 174 & 50.0 & \\
\hline Income Difficulty (Paying Bills) & & & $1.11(.98)$ \\
\hline No Difficulty & 116 & 33.3 & \\
\hline A Little Difficulty & 111 & 31.9 & \\
\hline Some Difficulty & 88 & 25.3 & \\
\hline Great Amount of Difficulty & 33 & 9.5 & \\
\hline
\end{tabular}


Appendix B

Model Modification Indices

\begin{tabular}{|c|c|c|c|c|c|c|}
\hline Model & $\mathrm{x}^{2}$ & df & $p$ & TLI & GFI & RMSEA \\
\hline 1. Baseline - All paths tested & 130.616 & 45 & $<.001$ & .864 & .948 & .074 \\
\hline \multicolumn{7}{|l|}{ Exploratory (dropping non-significant paths) } \\
\hline 2. Dropped Psychological WB $\leftarrow$ Gender & 134.161 & 46 & $<.001$ & .863 & .947 & .074 \\
\hline 3. Dropped Physical WB $\leftarrow$ Nutrition & 136.014 & 47 & $<.001$ & .864 & .946 & .074 \\
\hline 4. Dropped Physical Activity $\leftarrow$ Gender & 139.117 & 48 & $<.001$ & .864 & .945 & .074 \\
\hline 5. Dropped Physical Activity $\leftarrow$ Age & 141.472 & 49 & $<.001$ & .865 & .943 & .074 \\
\hline 6. Dropped Psychological WB $\leftarrow$ Employment & 142.753 & 50 & $<.001$ & .867 & .943 & .073 \\
\hline 7. Dropped Psychological WB $\leftarrow$ Age & 143.121 & 51 & $<.001$ & .871 & .943 & .072 \\
\hline 8. Dropped Nutrition $\leftarrow$ Gender & 149.630 & 52 & $<.001$ & .866 & .940 & .074 \\
\hline 9. Dropped Psychological WB $\leftarrow$ Education & 150.118 & 53 & $<.001$ & .869 & .940 & .073 \\
\hline 10. Dropped Physical WB $\leftarrow$ Age & 150.169 & 54 & $<.001$ & .873 & .940 & .072 \\
\hline 11. Dropped Nutrition $\leftarrow$ Gender & 150.898 & 55 & $<.001$ & .875 & .940 & .071 \\
\hline
\end{tabular}

Note. WB = Well-Being. 